\title{
IMPROVING THE QUALITY OF INFORMATION IN STRATEGIC SCANNING SYSTEM NETWORK: APPROACH BASED ON COOPERATIVE MULTI-AGENT SYSTEM
}

\author{
Yman CHEMLAL ${ }^{1}$, Hicham MEDROMI ${ }^{2}$ \\ ${ }^{1}$ (EAS- LISER) Systems Architecture Team, ENSEM, Hassan II University, BP.8118, \\ Oasis Casablanca \\ ${ }^{2}$ (EAS- LISER) Systems Architecture Team, ENSEM, Hassan II University, BP.8118, \\ Oasis Casablanca
}

\begin{abstract}
Integrating Business Intelligence (BI) processes in an information system requires a form of strategic scanning system for which the information is the main source of efficiency and decision support. A process of strategic scanning system network is primarily a cooperative approach to sharing knowledge that actors are "producers" of information. The dynamics of the actor's interactions allow gradual building of shared knowledge. This paper proposes Multi Agent System (MAS) architecture which facilitates the integration of a process of strategic scanning system network in the information system, to emerge relevant information from simple information while ensuring the quality and safety information. In particular, this approach is geared towards supporting system properties specially focused on cooperative multi-agent system. It gives finally an overview of implementation of a prototype of the proposed solution limited for the moment to the integration of processes most used in the majority of information systems.
\end{abstract}

\section{KEYWORDS}

Business Intelligence, strategic scanning system network, cooperative multi-agent system.

\section{INTRODUCTION}

"The Business Intelligence aims at enabling decision makers and managers of a company to have strategic Information. It therefore involves learning, observing, understanding an external environment and apprehending the events to make the best decisions for more competition and innovation.

This involves:

- Realize the routine monitoring of technological sectors and the market competition then the rational use of captured data,

- Know how to collect and use information.

This is a monitoring organized for decision support "[1]

The process of strategic scanning system is different from Business Intelligence; there is only one axis in the Business Intelligence process, as shown in this schematic presentation. (Figure 1) 


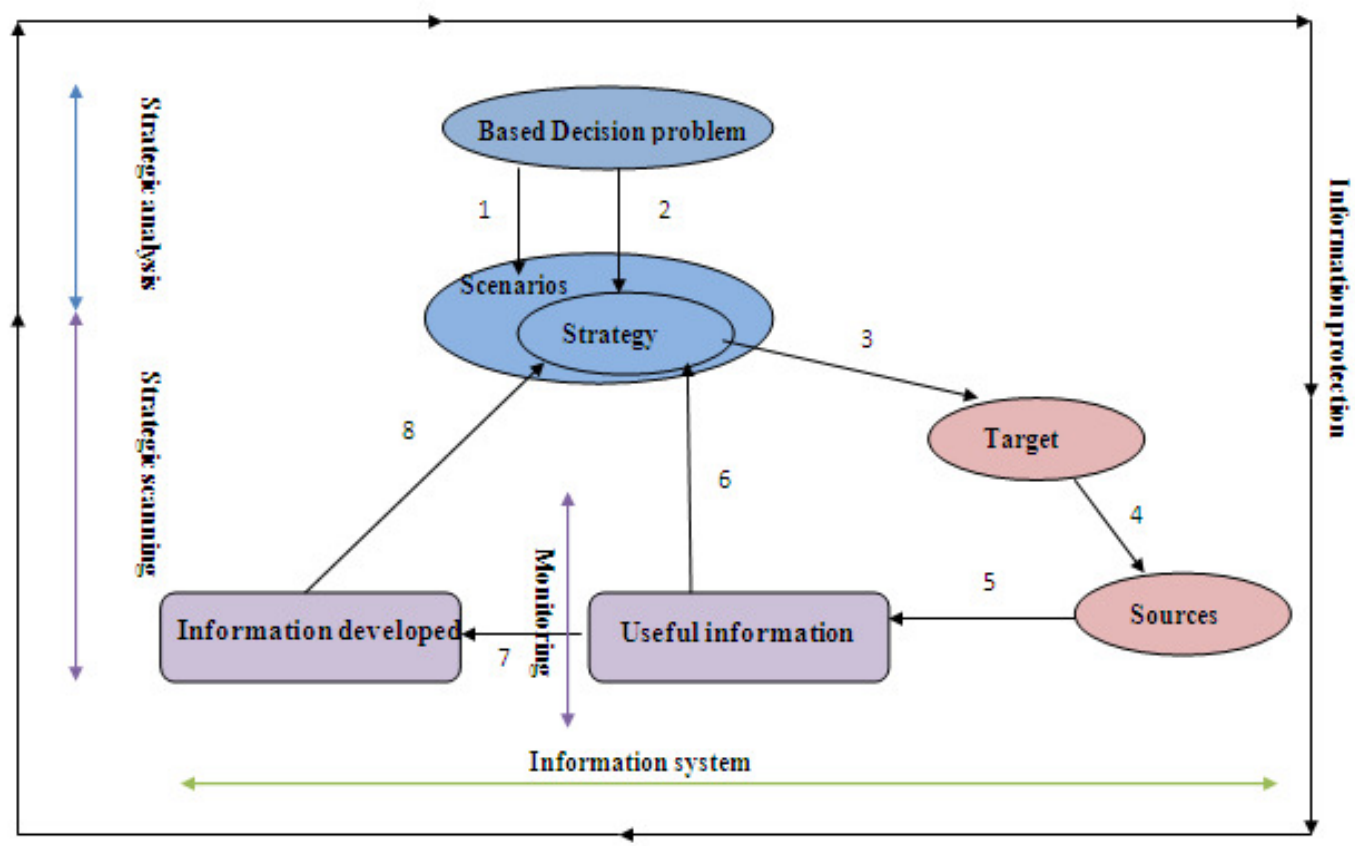

1 develop, 2 choose, 3 identify \& hierarchy, 4 identify \& select, 5 collect \& evaluate, 6 validate \& distribute, 7 analyze \& interpret, 8 validate \& distribute

Figure 1. Process Business Intelligence [2]

The axes related to BI approach: strategic analysis, monitoring, sources of information and information protection.

This is an informational process from research (tracking) information to their interpretation and using them to create a vision of the environment in which the company wants to carve out its place. This informational process is open to the outside of the company. It starts from its inside to go to the outside and then back inside during the information tracking. So this process crosses twice the organization's boundaries. [5]

"The Strategic scanning groups together all the monitoring activities (sales, marketing, competitive...) and is a proactive process of observation and analysis of the environment, followed by the targeted dissemination of information useful for decision "[1] (Figure 2)

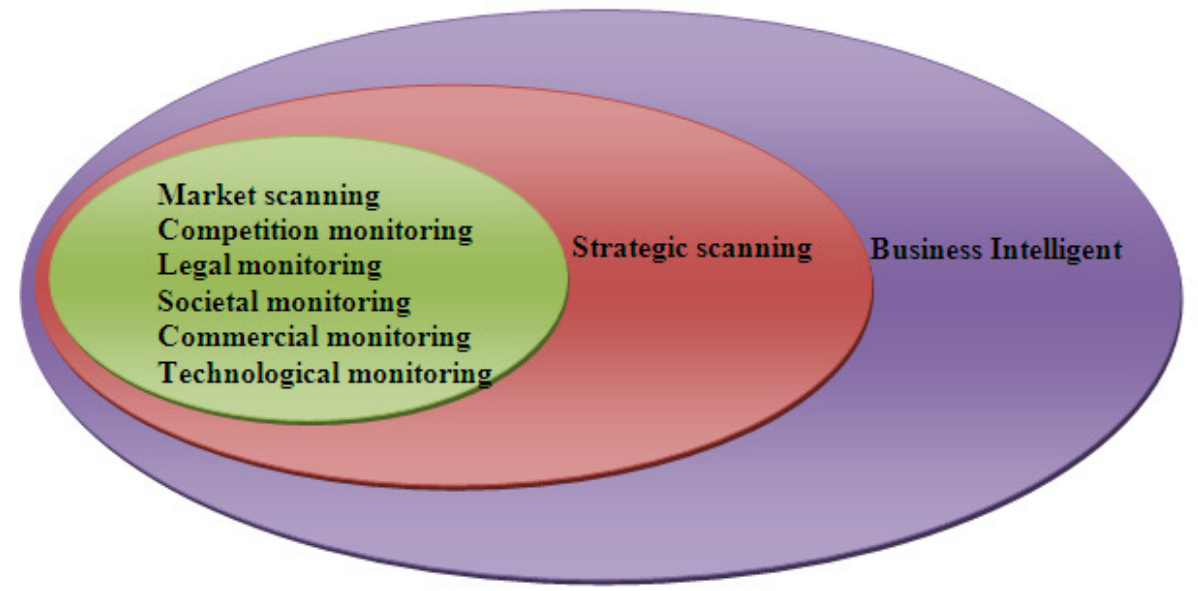

Figure 2. The concept of Strategic scanning system [1] 
The strategic scanning system is based on a strong idea: any actor in the company is likely to hold information elements and it is the synergy of these given elements which rise to usable information for action. [1]

This is a strategic scanning system network process which is primarily a knowledge sharing cooperative approach, where the exchange and sharing of information are essential both in the collection that analysis [4]. Figure 3 illustrates the role of Business Intelligence as a strategic scanning system network, in the production of useful information.

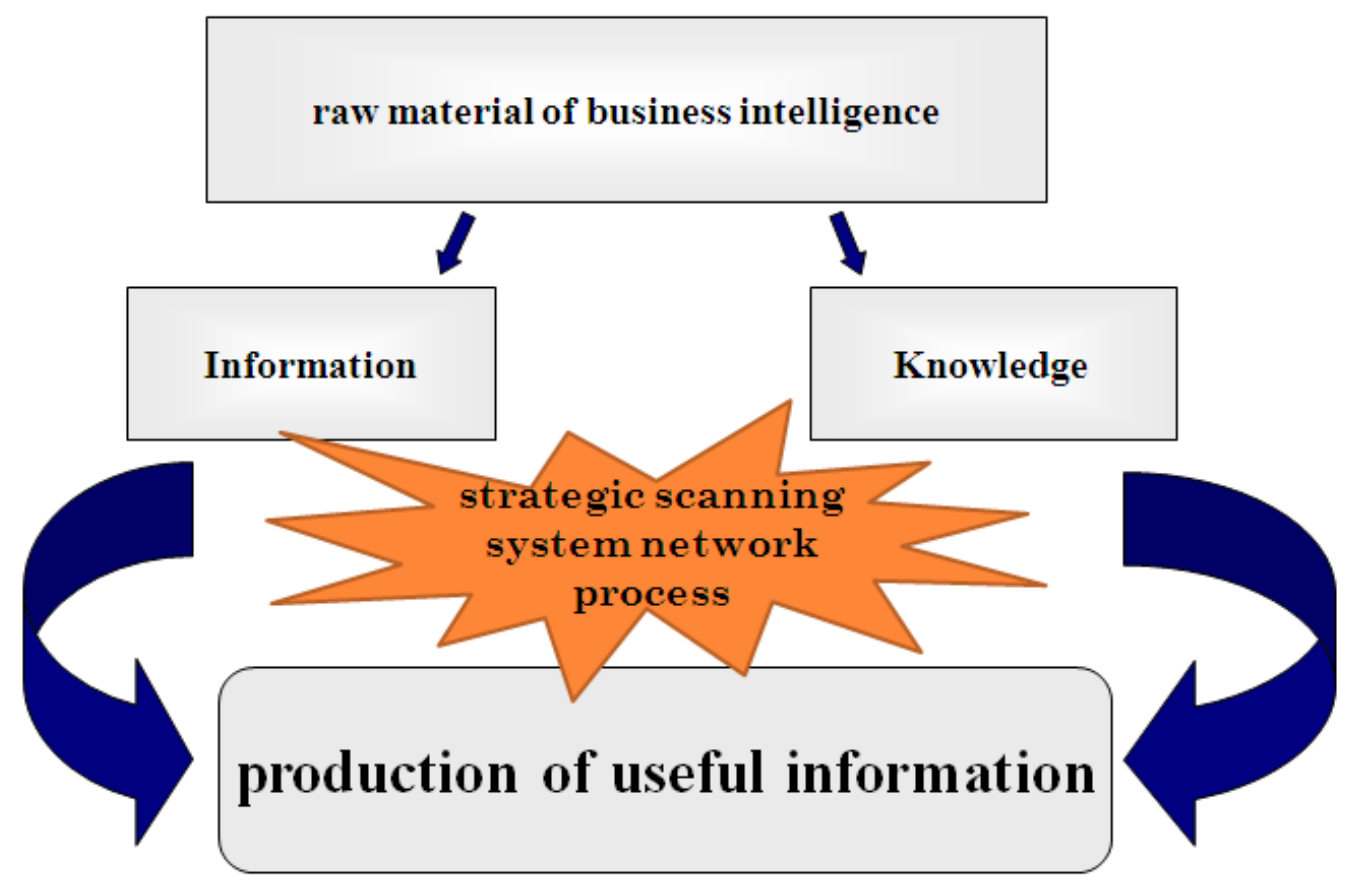

Figure 3. The role of Business Intelligence as a strategic scanning system network

However, this process is distributed, cooperative, coordinated and is characterized by a complexity of the dynamic interactions of the actors. In addition, it has a strong constraint of safety and quality of information. [4]

The goal of this research is then to design a platform able to integrate a process of strategic scanning system network in the information system, using cooperative MAS in order to adapt and make inferences from incomplete or uncertain information, taking into account the complexity and be able to self-organization. That is the system be able to: control the input, control partners' exchanges, validated information, updated the knowledge base, finally, distributed information to the views decision makers.

The remainder of the paper is organized as follows. Section 2 briefly discusses collective intelligence characteristics and some architecture enables share knowledge. Section 3 describes architecture of strategic scanning system network (SSSN) process. Section 4 discusses the application of the proposed architecture to the university's information system .Finally, a conclusion. 


\section{RELATED WORK}

As previously explained, we have introduced architecture able to facilitate the sharing of information. This process is carried out in such a way that the sharing of knowledge in collaboration between the actors involved in the information system be efficient and has an intelligent behavior.

In this sense, there exist several approximations of architectures. In Olivier Chator, Jean-Marc Salotti (2012), a solution focused on the implementation of a collaborative tool based on MAS where agents are skills, has been proposed [9] . In Victor Odumuyiwa (2009), a solution based on architecture for the development of an environment that enables communication between the actors to share knowledge, has been proposed [10]. In Amos David (2006), a proposal based on modeling (representation schema) of the actors' knowledge in the process of business intelligence, has been used [11]. In Amos David, Sahbi Sidhom (2005), a proposal focused on some models and tools for the implementation of the complex processes of Business Intelligent, has also been used [12]. In general terms, the methodologies and architectures discussed above primarily take an implementation point of view and focus heavily on developing a system able to facilitate communication and collaboration between actors to sharing of information. However, these architectures do not consider the dynamic interactions of the actors to share knowledge as well as the safety and quality of information.

This paper presents an architecture for developing Multi Agent System (MAS), supporting:

- the complex interactions (needs, requests, responses) users to gradually build knowledge shared as users' interactions,

- Security and quality of information.

In our approach, special attention is devoted to cooperative MAS and we adopt a phased approach. Each phase of our architecture development process is represented and formalized using architectural styles.

\section{IMPLEMENTATION OF ARCHITECTURE OF STRATEGIC SCANNING SYSTEM NETWORK (SSSN) PROCESS}

The Modeling of the platform is based on the principle of cooperative MAS which is every agent must cooperate to achieve the same goal. For this reason, we incorporate the general properties of cooperative MAS and suggest an essential architecture reflecting these properties.

\subsection{What is an agent?}

An agent is an entity (physical or abstract), characterized by the fact that it is autonomous in decision making, by the knowledge of itself and others, and its ability to act.

Experts in multi-agent systems have classified agents into three major categories according to an essential criteria that is the representation of its environment, these agents are: Reagents agents, Cognitive agents and Hybrid agents. [6]

\subsection{What is a multi agent system?}

A multi-agent system (MAS) is a distributed system consisting of a set of entities (programs)relatively independent agents, each with their own thread, specific to fulfill goals, and ways to communicate and negotiate with other to accomplish their goal. 
MAS are ideally designed as a set of agents interacting in cooperative, competitive and coexisting manner.

Multi agents systems are systems composed of the following elements:

- An environment with a metric in general.

- A set of objects, which can associate a position in an environment in a given time.

- Agents can perceive, create, destroy and modify these objects.

- A set of agents, which represents the active entities of the system,

- A set of relationships between agents between them.

- A set of operators that allow agents to perceive, produce, consume, transform and manipulate objects. [7] [8]

\subsection{Contribution of cooperative multi-agent system}

Indeed, a multi-agent system is very innovative because it is not based on a closed and hierarchical model. It is not based on predetermined and limiting representations. There is no a priori planning. It emerges post exchanges. The cooperative work network allows resolving temporarily the control of exchanges, since in this context everything is negotiable at once and permanently. [4]

\section{4 (SSSN) process architecture based on cooperative MAS}

As can be seen in Figure 4, the architecture defines three basic blocks which provide all functionalities of the architecture:

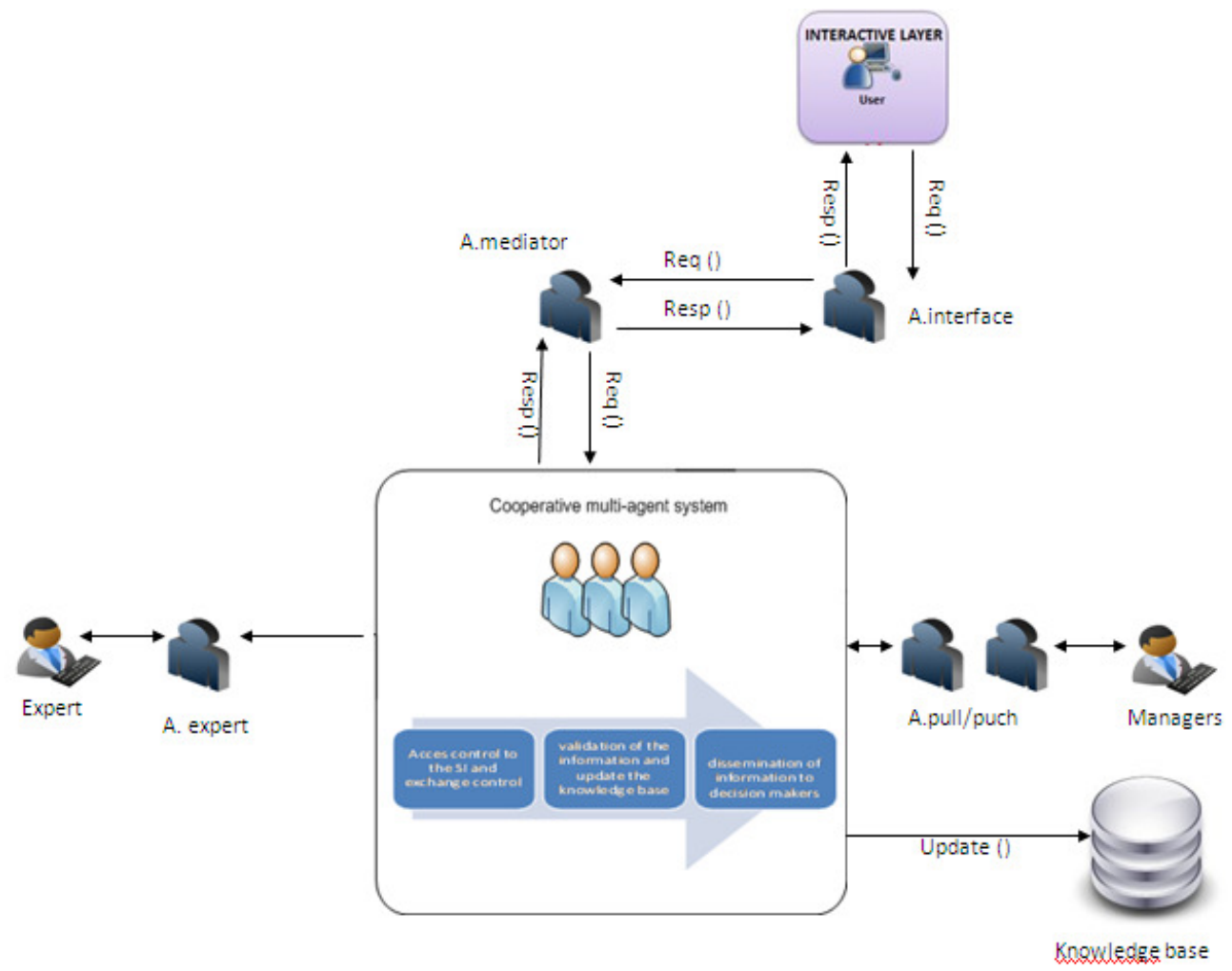

Figure 4. Global architecture model 


\subsubsection{Interface layer:}

This represents all the users that can use to exploit the system functionalities.

\subsubsection{Agents platform}

This system supports functionalities to resolve the issue of control of exchanges and the emergence of relevant information. As follows:

1- Access Control and exchange control,

2- Information Validated and Knowledge base Update,

3- Dissemination of information to decision makers.

\subsubsection{Access control and exchange control}

The monitoring network categorizes the actors and facilitates their interaction [4], on this, a communication control system between users and the access control system is proposed.

The first group of agents has a function in the system access control and exchange information.

Three types of agents at least are required:

- Interface Agent

- Agent usr / decision maker

- Agent strategic intelligence / mediator

Table 1. The first group of agents

\begin{tabular}{|c|c|c|}
\hline Agents & Type & Rôles \\
\hline $\begin{array}{l}\text { agent } \\
\text { interface }\end{array}$ & Reactive & $\begin{array}{l}\text { - Receive user requests and sends them to the agent usr / } \\
\text { decision maker }\end{array}$ \\
\hline $\begin{array}{l}\text { Agent usr / } \\
\text { decision } \\
\text { maker }\end{array}$ & hybrid & $\begin{array}{l}\text { - Receive interface agent requests and sends a response for } \\
\text { authentication. } \\
\text { - Define user requirements (request for information or } \\
\text { information production) } \\
\text { - analyse the level of knowledge of the user for a better } \\
\text { interpretation of its application (stores parameters necessary to } \\
\text { know the level of knowledge of the user) }\end{array}$ \\
\hline $\begin{array}{l}\text { Agent } \\
\text { strategic } \\
\text { intelligence } \\
\text { / mediator }\end{array}$ & cognitive & $\begin{array}{l}\text { - Receive requests from the agent usr / Decision Maker to record } \\
\text { users connected to the network. } \\
\text { - Check the connection with users } \\
\text { - Animate the network by launching discussions of general } \\
\text { interest } \\
\text { - Ensure compliance with the objectives of the network and the } \\
\text { clause of mutual exchange. } \\
\text { - update the knowledge base. }\end{array}$ \\
\hline
\end{tabular}




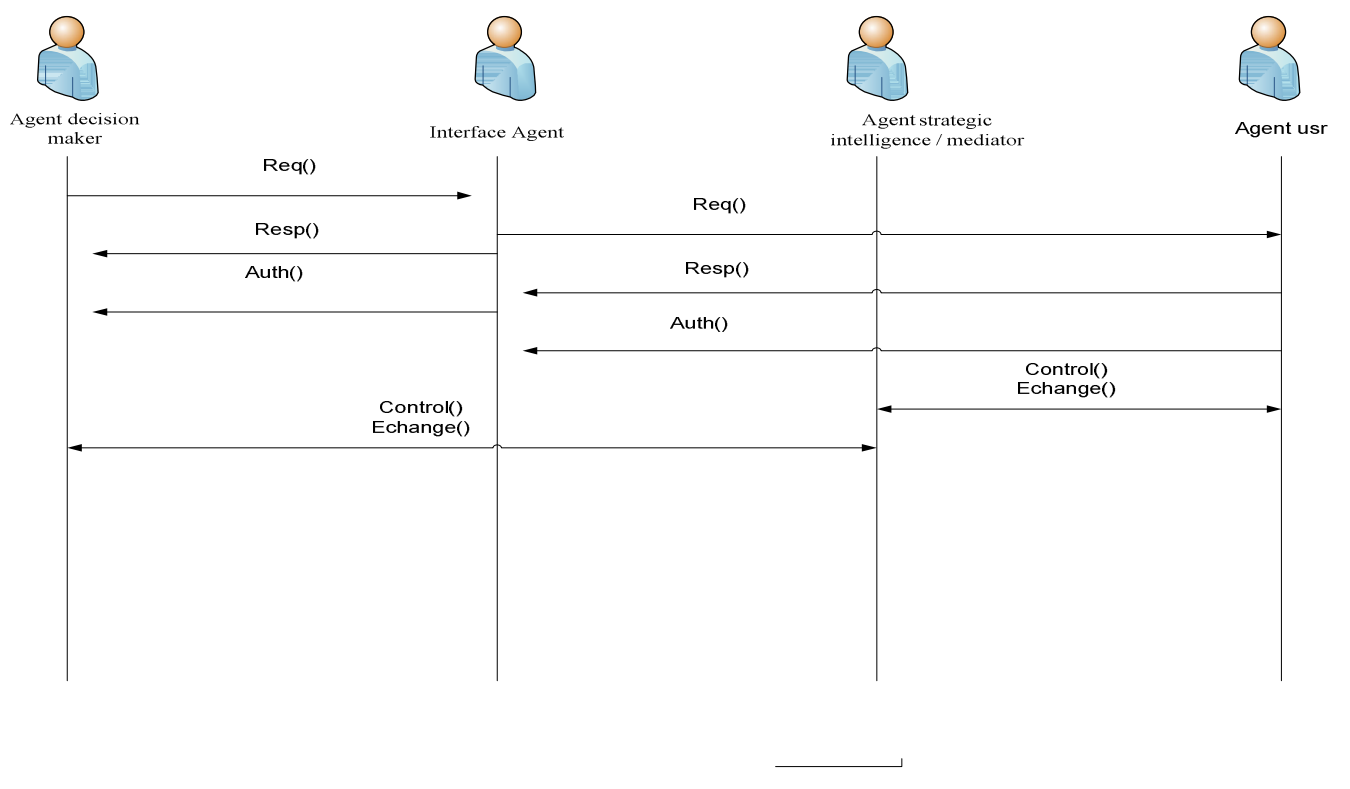

Figure 5. Plan model of the first group of agents

\subsubsection{Validation of information and update the knowledge base}

The creation of shared knowledge is the fundamental concept of this model (Effective participation of actors and basic communications between them).

On this, the second group is composed of three types of agents:

- Collector Agent

- Expert Agent

- Analyst Agent

Table 2.The second group of agents

\begin{tabular}{|l|l|l|}
\hline \multicolumn{1}{|c|}{ Agents } & \multicolumn{1}{|c|}{ Type } & \multicolumn{1}{c|}{ Rôles } \\
\hline $\begin{array}{l}\text { Collector } \\
\text { Agent }\end{array}$ & Cognitif & $\begin{array}{l}\text { - Collect information gathered by users, according to the source } \\
\text { and type of information } \\
\text { - Send requests to the expert agent to validate information }\end{array}$ \\
\hline $\begin{array}{l}\text { Expert } \\
\text { Agent }\end{array}$ & Reactive & $\begin{array}{l}\text { - Send requests to system experts with specific expertise in a } \\
\text { technical-economic field (scientific, technical, technological, } \\
\text { legal or financial, etc.) to confirm the information exchanged. } \\
\text { - Receive answers from system experts }\end{array}$ \\
\hline $\begin{array}{l}\text { Analyst } \\
\text { Agent }\end{array}$ & Hybride & $\begin{array}{l}\text { - Receive information validated by the expert agent } \\
\text { - Sends validated information to the mediator agent } \\
\text { - Graph information. } \\
\text { - Archived useful information to decision makers. } \\
\text { - Generate reports on demand for decision makers. }\end{array}$ \\
\hline
\end{tabular}




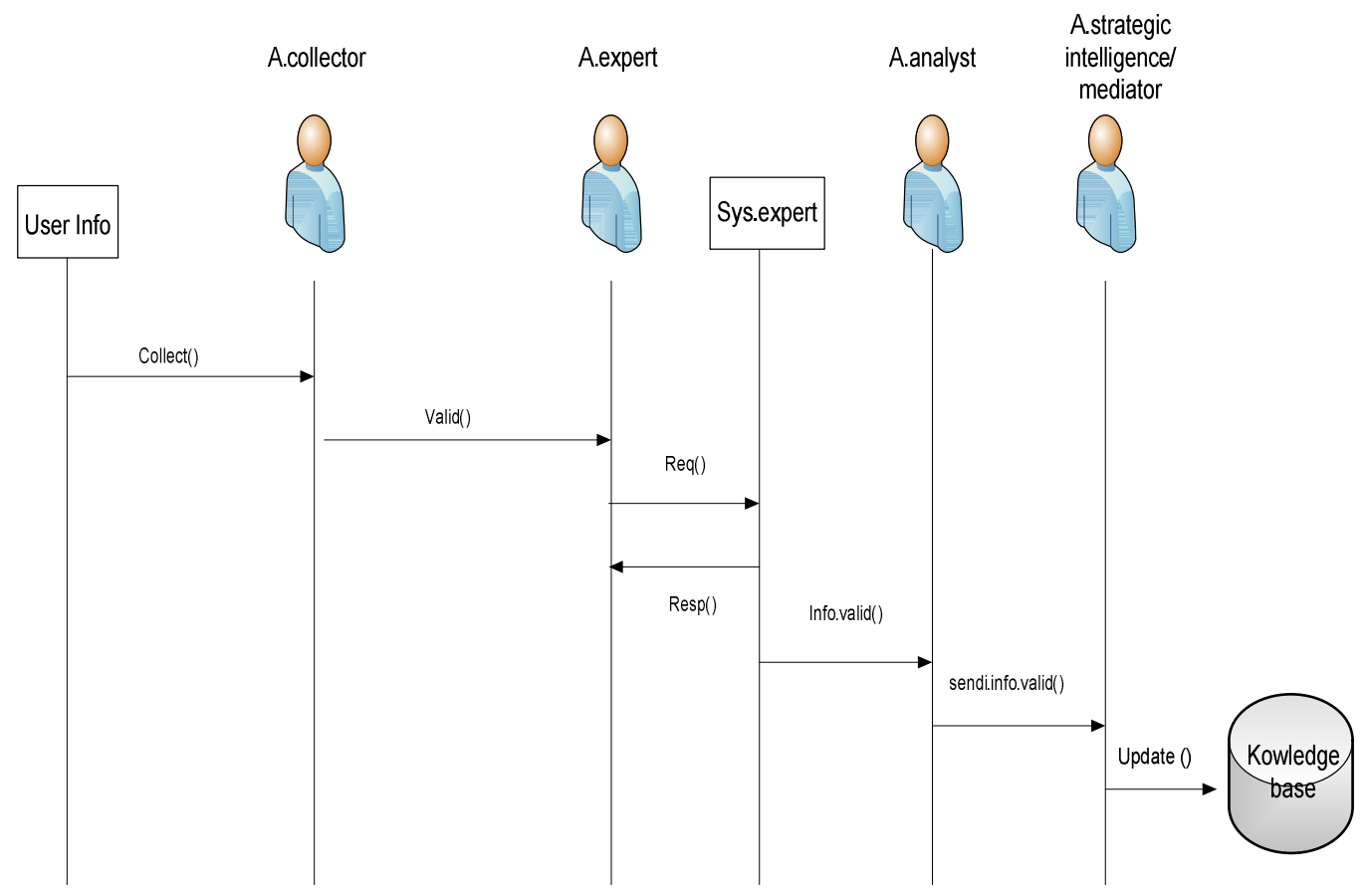

Figure 6. Plan model of the second group of agents

\subsubsection{Diffusion of information to decision makers}

The system must include the model "PULL" and "PUSH", that is to say, provide the decision maker with the ability to request information on profile and be informed when events occur. In this case, the two types of agents proposed for the third group are:

Table 3.The third group of agents

\begin{tabular}{|l|l|l|}
\hline Agents & Type & Rôles \\
\hline Agent pull & Cognitif & $\begin{array}{l}\text { Provide the decision maker the opportunity to request information } \\
\text { on profile }\end{array}$ \\
\hline Agent push & Cognitif & To be informed when updates of the knowledge base occurs. \\
\hline
\end{tabular}

\subsubsection{Knowledge base}

In the field of business intelligence, information itself is of relatively low interest. It is the interpretation of this information and comments that are essential. [5]

That is why we are led to introduce a knowledge base. This part of the system includes all the data and tables used by all components of the platform, including static data, the information shared between actors and interpreted by the group of experts., indicators related to agents, appropriate decisions to the various scenarios of behavior to be submitted to Query Agent depending on the state of the collaboration between process agents and knowledge of users. 


\subsection{The global architecture}

The architecture illustrated in the Figure 7 presents the first and the second group of our approach that allows improving a quality of information in the Strategic scanning system network.

The proposed model is a modular multi-agents architecture where all components are managed and controlled by different types of agents which are able to cooperate, propose solutions for very dynamic environments and face real problems.

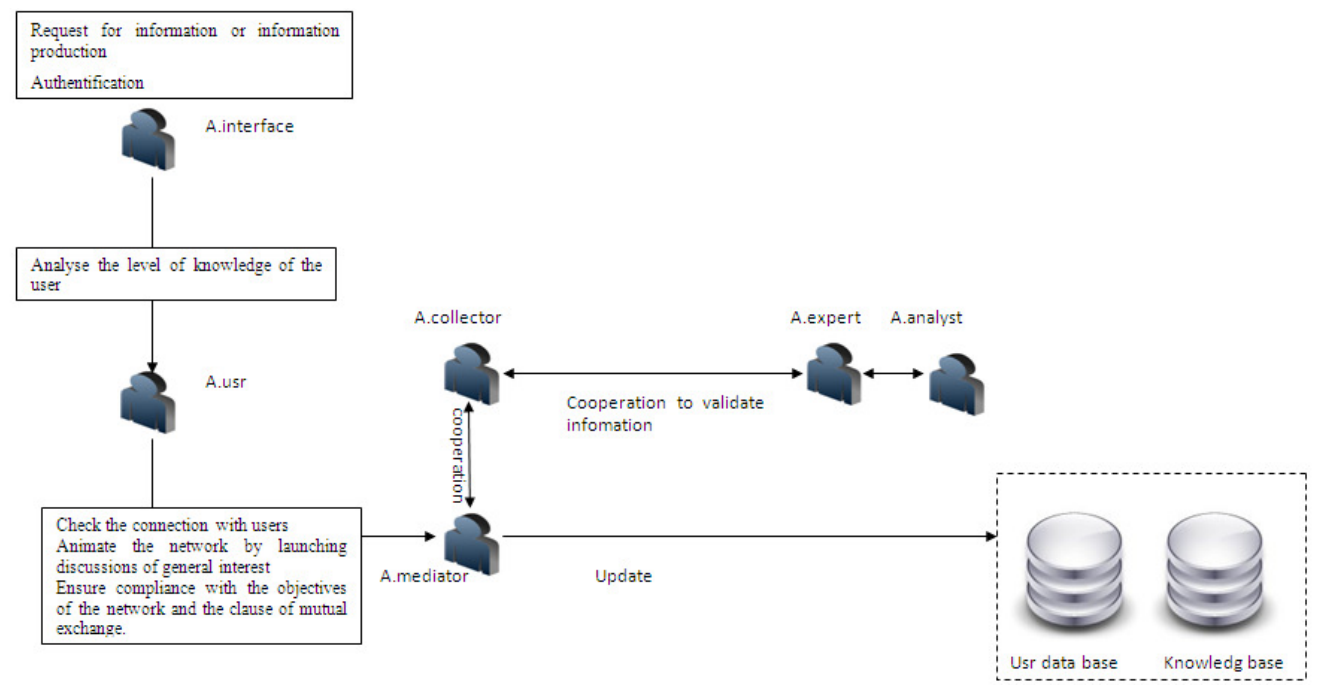

Figure 7. Modeling of the first and second group of MAS which ensures the good functioning of SSSN process

\section{Application Cases}

We will apply our approach to the university information system to highlight some of the key features of our approach. The university's information system is our scope; because we are in a training environment where the actors move using library resources management systems, production information systems and information retrieval systems. Educational technology devices make available: courses, projects accessible through the sharing of information systems, where the actor evolves in a collaborative information system [13]. Our approach helps to develop the university's information systems into a strategic information system, where actors become an information producer. Figure 8 illustrates the general architecture of collaborative information Production in a university information system. 


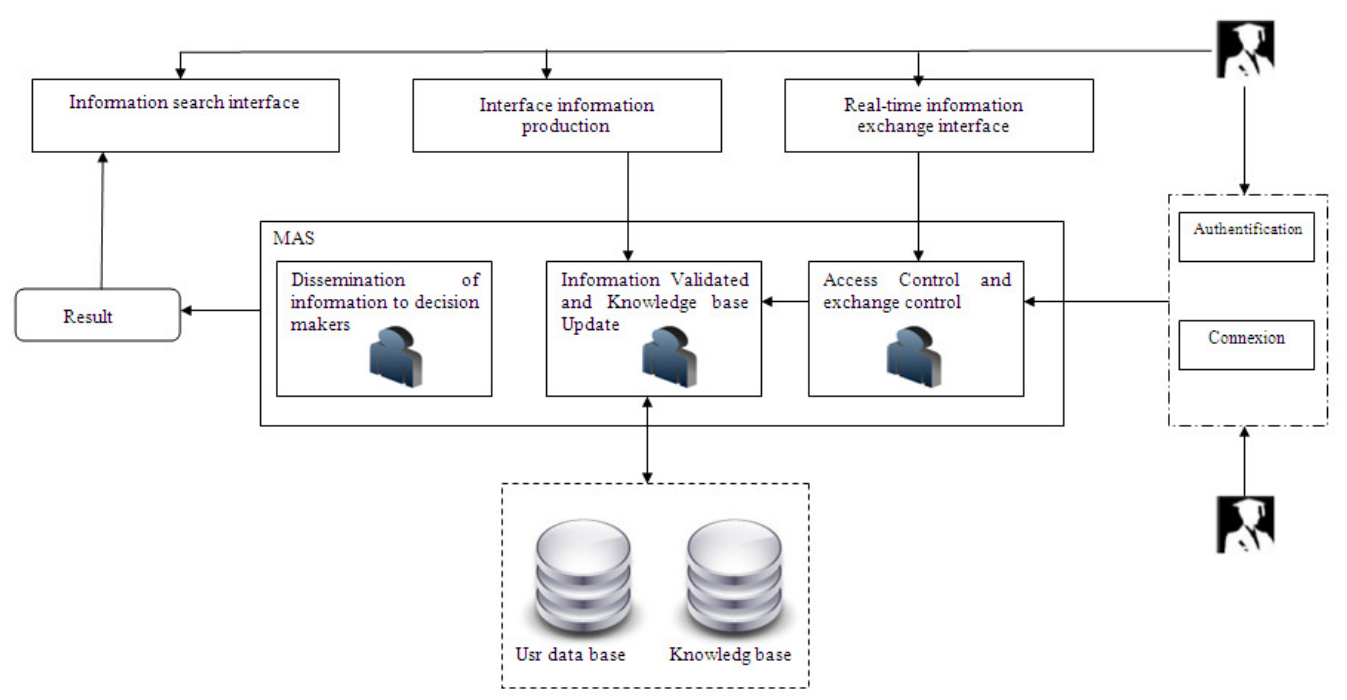

Figure 8. Architecture of collaborative information Production

The starting point in the system is the authentication interface, we noticed that most of information production system is used when trust is total and all the skills and experience employees are centralized [11], However to ensure the quality of information produced by our intelligence network we introduced a agent usr/decision maker to validate the level of knowledge of the user for a better interpretation of its application by storing parameters necessary to know the level of knowledge of the user.

In our approach to introduce collaborative intelligence, we allow the user to interact with the monitoring network using the strategic intelligence / mediator Agent, that can check the connection with the Users, Animate the network by launching discussions of interest generally, ensure respect for the objectives of the network and the clause of mutual exchange.

The knowledge base is updated by the information shared in real time by users or the information sent by users at the deferred time and validated by coordinating collector Agent, expert agent, analyst agent, for both user collaboration modes.

The proposed approach also enables respond to the information search requests according to user profile (student / teacher / administrative), and distribute relevant information to decision makers.

\section{CONCLUSION \& FUTURE WORK}

We have shown in this article the importance of economic intelligence as a network monitoring in sharing and production of information in an information system. However this system should combine networking, must be able to adapt and make inferences from incomplete or uncertain information and be able to self-organization.

To respond to these requirements, this paper has proposed a platform able to integrate a process of strategic scanning system network in the information system, using cooperative MAS, taking into account the dynamic interactions of the actors to share knowledge as well as the safety and quality of information. 
This architecture proposed allows to: control the input, control partners' exchanges, validated information, updated the knowledge base, finally, distributed information to the views decision makers.

This approach is geared towards supporting system properties specially focused on cooperative multi-agent system where all components are managed and controlled by different types of agents which are able to cooperate, propose solutions on very dynamic environments and face real problems.

To prove the performance of this proposal, we have presented an implementation of our approach as architecture from a real case study; it is a university information system.

As future enhancements we would like to extend our model by defining a detailed architecture of each agent, specifying communication between these agents using ACL (Agent Communication Language) [14] and implementing the architecture proposed in the SMA development platform Jade (Java Agent Development Framework) [15].

\section{REFERENCES}

[1] Institut Atlantique d'Aménagement des Territoires (IAAT) (2005), « la veille stratégique du concept au pratique »,

[2] A.ELHADDADI, (2011), « fouille multidimensionnelle sur les données textuelles visant à extraire les réseaux sociaux et sémantique pour l'exploitation via la téléphone mobile ».

[3] LINK-PEZET Jo, R.BERKANE, D. MOTTAY, « intelligence économique et décision ».

[4] Humbert LESCA, «Veille stratégique, Concepts et démarche de mise en place dans l'entreprise ».

[5] S. elhasnaoui, H. medromi, S.faris, H.iguer, A. sayouti,( 2014) «Designing a Multi Agent System Architecture for IT Governance Platform», IJACSA, Vol. 5, No.

[6] Dante I. Tapia, Sara Rodríguez, Javier Bajo, Juan M. Corchado, FUSION, A SOA Based Multi-Agent Architecture

[7] Sayouti, F. Moutaouakkil, H. Medromi (2010). "The Interaction- Oriented Approach for Modeling and Implementing Multi-Agent Systems", International Review on Computers and Software (I.RE.CO.S)

[8] Olivier Chator Jean-Marc Salotti (2012), «Modélisation Multi-Agents centrée sur les Compétences pour la Collaboration des Acteurs dans les Projets de Développement Durable

[9] Victor Odumuyiwa (2009), « La collaboration dans la résolution de probléme informationnel : application dans un projet d'intelligence économique »

[10] Amos David (2006), « La recherche collaborative d'information dans un contexte d'Intelligence Economique »

[11] Amos David, Sahbi Sidhom (2005), « intégration de la démarche d'Intelligence Economique dans l'architecture fonctionnelle d'un système d'information »

[12] Frederique Peguiron (2006), « Application de l'Intelligence Economique dans un Système d'Information Stratégique universitaire : les apports de la modélisation des acteurs »

[13] Badr Benmammar (2009), «système multi agent »

[14] Olivier Boissier (2010), «JADE Environnement pour la programmation multi-agent »

\section{Authors}

Yman CHEMLAL is an engineer in computer science from the INPT, in July 2005, Rabat, Morocco. She prepares her thesis at ENSEM, Hassan II University, Casablanca, Morocco.

Hicham Medromi received the $\mathrm{PhD}$ in engineering science from the Sophia Antipolis University in 1996, Nice, France. He is responsible of the system architecture team of the ENSEM Hassan II University, Casablanca, Morocco. His actual main research interest concern Control Architecture, Architecture of System and Software Architecture Based on Multi Agents Systems and Distributed Systems. Since 2003 he is a full professor for Control systems and computer sciences at the ENSEM, Hassan II University, Casablanca. He managed eight Research projects and he has published several Patents and publications in international journals and conferences. 